\title{
Evaluation of the reference value for the Montenegro skin test
}

\author{
Cissiara Manetti Skraba [1], Tatiane França Perles de Mello ${ }^{[1]}$, Raíssa Bocchi Pedroso ${ }^{[1]}$, \\ Érika Cristina Ferreira ${ }^{[1]}$, Izabel Galhardo Demarchi ${ }^{[1]}$, Sandra Mara Alessi Aristides ${ }^{[2]}$, \\ Maria Valdrinez Campana Lonardoni ${ }^{[2]}$ and Thaís Gomes Verzignassi Silveira ${ }^{[2]}$
}

[1]. Programa de Pós-Graduação Stricto Sensu em Ciências da Saúde, Universidade Estadual de Maringá, Maringá, Paraná, Brasil. [2]. Departamento de Análises Clínicas e Biomedicina, Universidade Estadual de Maringá, Maringá, Paraná, Brasil.

\begin{abstract}
Introduction: The Montenegro skin test (MST) has good clinical applicability and low cost for the diagnosis of American tegumentary leishmaniasis (ATL). However, no studies have validated the reference value $(5 \mathrm{~mm})$ typically used to discriminate positive and negative results. We investigated MST results and evaluated its performance using different cut-off points. Methods: The results of laboratory tests for 4,256 patients with suspected ATL were analyzed, and 1,182 individuals were found to fulfill the established criteria. Two groups were formed. The positive cutaneous leishmaniasis (PCL) group included patients with skin lesions and positive direct search for parasites (DS) results. The negative cutaneous leishmaniasis (NCL) group included patients with skin lesions with evolution up to 2 months, negative DS results, and negative indirect immunofluorescence assay results who were residents of urban areas that were reported to be probable sites of infection at domiciles and peridomiciles. Results: The PCL and NCL groups included 769 and 413 individuals, respectively. The mean \pm standard deviation MST in the PCL group was $12.62 \pm 5.91 \mathrm{~mm}$ [95\% confidence interval (CI): 12.20-13.04], and that in the NCL group was $1.43 \pm 2.17 \mathrm{~mm}$ (95\% CI: $1.23-1.63$ ). Receiver-operating characteristic curve analysis indicated $97.4 \%$ sensitivity and $93.9 \%$ specificity for a cut-off of $5 \mathrm{~mm}$ and $95.8 \%$ sensitivity and $97.1 \%$ specificity for a cut-off of $6 \mathrm{~mm}$. Conclusions: Either $5 \mathrm{~mm}$ or $6 \mathrm{~mm}$ could be used as the cut-off value for diagnosing ATL, as both values had high sensitivity and specificity.
\end{abstract}

Keywords: Cutaneous leishmaniasis. Montenegro skin test. Cut-off value. Diagnosis.

\section{INTRODUCTION}

Leishmaniasis can affect the skin, mucous membranes, and internal organs in humans and other mammals. There are 310 million people in 6 countries at risk of infection, with 1 million cases of cutaneous leishmaniasis reported in the last 5 years, 300,000 estimated cases of visceral leishmaniasis, and over 20,000 deaths annually ${ }^{(1)}$. In the Americas, cutaneous leishmaniasis occurs in the geographic area ranging from southern United States to northern Argentina, with the exception of Chile and Uruguay.

American tegumentary leishmaniasis (ATL) is widely distributed from northern to southern Brazil. From 1990 to 2013, 635,399 cases of ATL were reported in Brazil, 13,889 from the southern region and 95\% from the State of Paraná, from

Corresponding author: Dra. Thaís Gomes Verzignassi Silveira. Depto. de Análises Clínicas e Biomedicina/UEM. Av. Colombo 5790, Jardim Universitário, 87020-900 Maringá, Paraná, Brasil.

Phone: 55443011 4878; Mobile: 554499727526

e-mail: tgvsilveira@uem.br

Received 4 March 2015

Accepted 29 June 2015
276 of the 399 municipal districts ${ }^{(2)}$ (3). Deforestation, urbanization, and the consequent invasion of vectors in the peridomicile have increased the incidence of $\mathrm{ATL}^{(4)}$. The main species of Leishmania that cause ATL in Brazil are Leishmania (Viannia) braziliensis, Leishmania (Viannia) guyanensis, and Leishmania (Leishmania) amazonensis ${ }^{(4)}$.

The diagnosis of ATL is based on epidemiological, clinical, and laboratory data, including parasitological and immunological techniques ${ }^{(5)(6)(7)}$. An association between two or more techniques provides a more valid diagnosis of ATL. The direct search (DS) for parasites is performed by identifying amastigote forms in smears of the lesion. However, sensitivity decreases with lesion progression. The immunological methods include the Montenegro skin test (MST) to detect delayed hypersensitivity and indirect immunofluorescence (IIF) and enzyme immunoassay (EIA) to search for antibodies. The antibody search tests are sensitive and specific, but they are associated with cross-reactivity with other diseases, mainly Chagas disease and visceral leishmaniasis ${ }^{(6)(7)}$.

The MST was introduced in 1926 by Montenegroto to diagnose ATL with good clinical applicability and low $\operatorname{cost}^{(8)}$. The antigen is inoculated in the forearm of the patient, and the reaction is read after $48 \mathrm{~h}^{(5)}$. The reaction is characterized by induration at the inoculation site due to abundant infiltration of lymphocytes and macrophages ${ }^{(9)}$. A diameter of $\geq 5 \mathrm{~mm}$ is 
considered to indicate a positive reaction. The MST is useful in cases in which the parasites are scarce or absent (i.e., when the ATL lesion has undergone more than 2 months of evolution) and in epidemiological surveys in endemic areas ${ }^{(5)}$.

The criteria for defining a positive result on skin tests for delayed hypersensitivity vary among authors, but a positive test result is considered when the induration diameter is $\geq 5 \mathrm{~mm}^{(10)}$. Similarly, with the MST, authors have considered diameters $\geq 5 \mathrm{~mm}$ as a positive test result ${ }^{(8)(9)(11)(12)(13)(14)(15)(16)(17)}$. Reaction diameters $\geq 6 \mathrm{~mm}$ have also been reported ${ }^{(18)(19)}$. However, no studies have validated the reference value $(5 \mathrm{~mm})$ that is typically used to discriminate positive and negative MST results for ATL. The objective of the present study was to analyze MST results and evaluate different cut-off values for the diagnosis of ATL.

\section{METHODS}

In this retrospective, descriptive, analytical study, we analyzed laboratory test results of patients with suspected American tegumentary leishmaniasis (ATL) who were referred by the $15^{\text {th }}$ Regional Health Division of the State of Paraná and attended the Laboratório de Leishmanioses of the Laboratório de Ensino e Pesquisa em Análises Clínicas, Universidade Estadual de Maringá (LEPAC/UEM) between June 1999 and February 2014. The available epidemiologic data included sex, age, place of residence and work (rural or urban), lesion characteristics, number of lesions, and duration of lesion evolution. The tests used for laboratory diagnosis included DS for parasites by microscopy, IIF, and the MST.

The DS was performed with tissue obtained by scarification of the edge of the lesion, which was smeared on a slide and stained with Giemsa. Indirect immunofluorescence was performed with L. (V.) braziliensis promastigotes and anti-human immunoglobulin $\mathrm{G}$ conjugated to fluorescein, with positive titers considered as $\geq 40$. The MST used dead $L$. (L.) amazonensis promastigotes that contained $40 \mu \mathrm{g}$ protein nitrogen $/ \mathrm{mL}$ supplied by the Centro de Produção e Pesquisa em Imunobiológicos (CPPI), State of Paraná, Brazil. Briefly, $0.1 \mathrm{~mL}$ of the antigen was intradermally injected into the anterior surface of the forearm. The induration diameter at the injection site was measured $48 \mathrm{~h}$ later using a millimeter-graduated ruler and ballpoint pen ${ }^{()}$.

\section{Statistical analysis}

For analysis, patients who underwent the MST were selected based on the presence of skin lesions. To evaluate the cut-off point for the MST, two groups were formed based on laboratory results and clinical and epidemiological data according to criteria that define the epidemiologic characteristics of ATL in Northwestern Paraná(20). The positive ATL [positive cutaneous leishmaniasis (PCL)] group included patients with skin lesions and positive DS results. The negative ATL [negative cutaneous leishmaniasis (NCL)] group included patients with skin lesions of an evolution up to 2 months, negative DS results, and negative IIF results who were residents in urban areas and reported to be probable sites of infection at domiciles and peridomiciles.

The data were plotted in Microsoft Excel 2010 spreadsheets. Quantitative data are described using mean \pm standard deviation.
For comparisons of means, Student's $t$-tests were used. The Z test was used to compare proportions. Sensitivity and specificity values were used to construct receiver-operating-characteristic (ROC) curves to analyze different reference values (cut-off values) for all of the patients. Statistical analysis was performed using Statistica 8.0 software, with a $5 \%$ level of significance $(p<0.05)$.

\section{Ethical considerations}

The procedures followed the Resolution 466/2012 of the National Health Council of the Brazilian Ministry of Health, and ethical approval was obtained from the Comitê Permanente de Ética em Pesquisa Envolvendo Seres Humanos of the Universidade Estadual de Maringá (Report 744.556, July 14, 2014). The procedures followed were in keeping with the Helsinki Declaration of 1964, as revised in 1975, 1983, 1989, 1996, and 2000.

\section{RESULTS}

Of the 4,256 patients initially evaluated, 1,182 were selected for inclusion (Figure 1) based on the epidemiological data and laboratory results. These patients had a mean age of $40.34 \pm 17.80$ years and mean MST induration diameter of $8.71 \pm 7.27 \mathrm{~mm}$ (Table 1). Patient age in the PCL group $(\mathrm{n}=769)$ was $39.58 \pm 16.38$ years (range, $1-86$ years) and that in the NCL group $(\mathrm{n}=413)$ was $41.76 \pm 20.12$ years (range, $1-90$ years). The MST induration diameters of the PCL and NCL groups were $12.62 \pm 5.91 \mathrm{~mm}$ (range, $0-44 \mathrm{~mm}$ ) and $1.43 \pm 2.17 \mathrm{~mm}$ (range, $0-15 \mathrm{~mm})$, respectively $(\mathrm{p}<0.01)$.

The PCL group had more men $(632 / 769)$ than women $(137 / 769 ; \mathrm{p}<0.01)$. The mean age of the men $(39.82 \pm 15.83$ years $)$ was similar to that of women $(38.50 \pm 18.76$ years; $p=0.32)$. The mean induration diameter in men $(12.51 \pm 5.73 \mathrm{~mm})$ was also similar to that of women $(13.11 \pm 6.67 \mathrm{~mm} ; \mathrm{p}=0.28)$. The numbers of men and women in the NCL group were similar (210/413 and $203 / 413$, respectively; $p=0.68$ ), as were the mean ages of men and women $(42.05 \pm 20.20$ years and $41.45 \pm 20.10$ years; $p=0.76)$. The mean induration diameter in men $(1.65 \pm 2.57 \mathrm{~mm})$ was significantly different from that in women $(1.20 \pm 1.64 \mathrm{~mm} ; \mathrm{p}=0.03)$.

Based on ROC curve analysis (Figure 2), the sensitivity and specificity for a $5 \mathrm{~mm}$ cut-off value were $97.4 \%$ and $93.9 \%$, respectively. The sensitivity and specificity for a $6 \mathrm{~mm}$ cut-off value were $95.8 \%$ and $97.1 \%$, respectively.

Receiver-operating-characteristic curves are shown according to sex in Figure 3. The best curve was found for women who had higher specificities for the two cut-off points. Figure 4 shows the ROC curves according to age (0-14 years, $15-29$ years, $30-49$ years, and $\geq 50$ years). The best curve was observed for patients who were 0-14 years old.

\section{DIscussion}

Since June 1999, LEPAC/UEM has performed the MST with an antigen from the Brazilian Ministry of Health that is produced in large scale according to good-practice standards of the Centro de Produção e Pesquisa em Imunobiológicos ${ }^{(21)}$ 


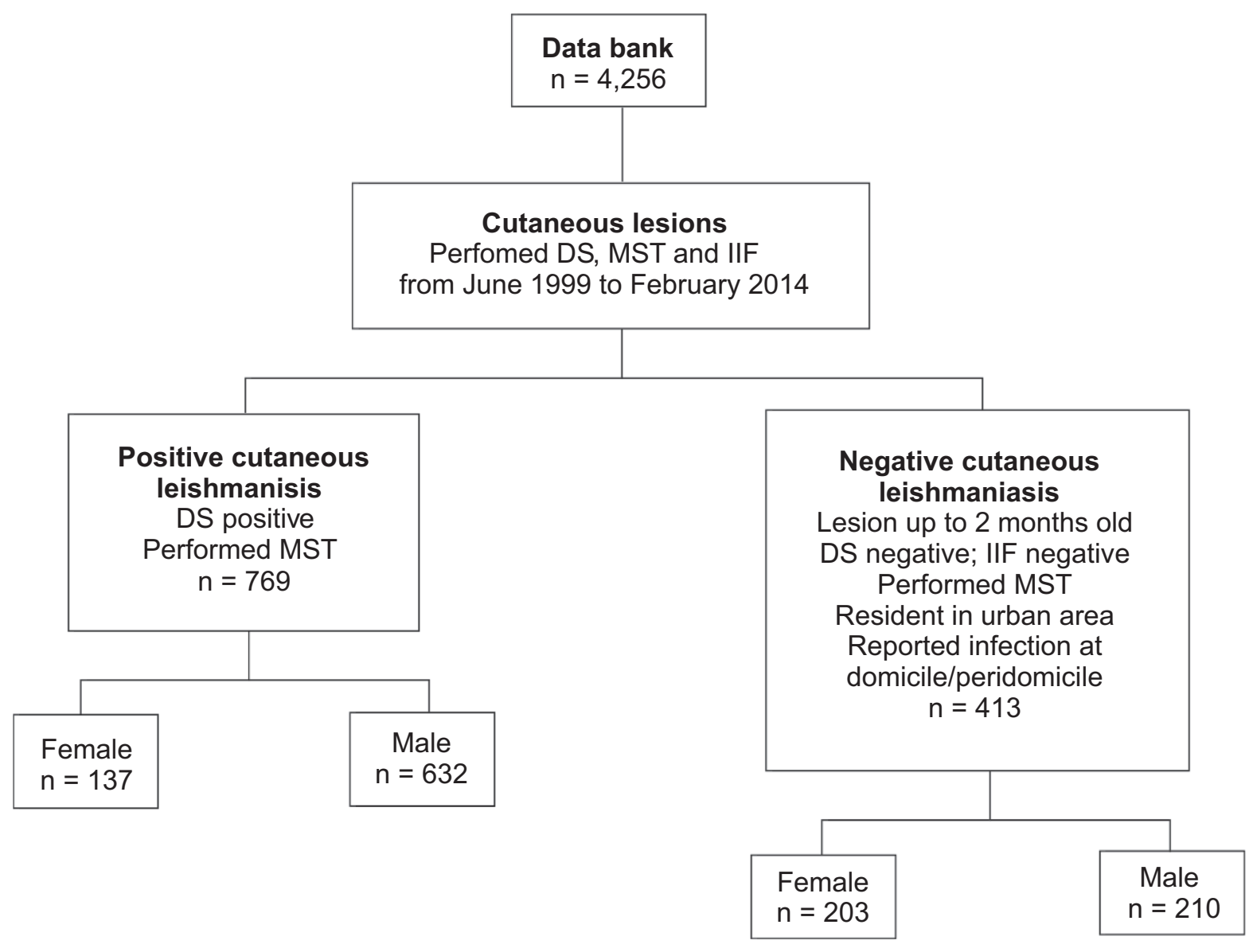

FIGURE 1 - Selection of groups after analysis from Laboratório de Leishmanioses of the LEPAC/UEM in Maringá, State of Paraná, Brazil, 1986 to 2014. DS: direct search of parasite; MST: Montenegro skin test; IIF: indirect immune fluorescence; LEPAC/UEM: Laboratório de Ensino e Pesquisa em Análises Clínicas, Universidade Estadual de Maringá.

of the Secretaria de Estado da Saúde do Paraná, Brazil. The importance of standardizing the application and reading of the MST has been highlighted by several authors. The test must be performed by a trained technician to ensure comparable results and avoid common causes of variation in the execution and interpretation of the tests ${ }^{(22)}{ }^{(23)}$. Patients who attend LEPAC/ UEM always undergo a standard protocol that ensures the quality of test performance.

American tegumentary leishmaniasis is known to affect more individuals who live in rural areas. Ninety percent of patients have lesion times up to 2 months, during which time most patients show positive MST and DS results. Thus, the PCL group consisted of patients with positive $\mathrm{DS}$ results, and the NCL group consisted of patients with a lesion time up to 2 months and negative DS and IIF results who resided in urban areas. This strategy for the NCL group was employed because the MST, which applies Leishmania antigens, is not recommended for normal individuals; it could lead to sensitization and falsepositive results if the MST is required in the future. In healthy subjects who underwent the MST and had tested negative in a previous study, $50 \%$ had a positive test when the MST was performed again after 90 days, and $\gamma$-IFN produced by peripheral blood mononuclear cells stimulated with Leishmania antigens was detected in $78 \%$ of subjects 360 days after the initial MST ${ }^{(24)}$. However, other authors observed no positivity with the MST with $\mathrm{a} \geq 1$-year interval between two tests ${ }^{(22)}$.

Comparisons between the PCL and NCL groups showed differences in the mean age of the individuals and the induration diameter. The latter was expected because the PCL group had a parasitological diagnosis of ATL. In addition, the PCL group consisted of more men than women, which is consistent with the literature that indicates that men engage in more rural leisure activities, such as fishing, than women ${ }^{(20)(25)}$. Within the PCL group, the mean age and mean induration diameter were not different between the sexes. Similarly, the number of men and women and their mean ages were similar within the NCL group; however, the mean induration diameter was higher in men.

The ROC curve that was constructed for the PCL and NCL groups indicated that the MST cut-off could be either $5 \mathrm{~mm}(97.4 \%$ sensitivity and $93.9 \%$ specificity) or $6 \mathrm{~mm}$ 
TABLE 1 - Characteristics of 1,182 patients (PCL and NCL groups) according to sex, age, and diameter with the Montenegro skin test.

\begin{tabular}{|c|c|c|c|c|c|c|}
\hline Groups & \multicolumn{3}{|c|}{ Age (years) } & \multicolumn{3}{|c|}{ Induration (mm) } \\
\hline PCL $(n=769)$ & $1-86$ & $39.58 \pm 16.38$ & $38.42-40.74$ & $0-44$ & $12.62 \pm 5.91$ & $12.20-13.04$ \\
\hline women $(n=137)$ & $3-86$ & $38.50 \pm 18.76$ & $35.33-41.67$ & $1-44$ & $13.11 \pm 6.67$ & $11.11-14.23$ \\
\hline $\operatorname{men}(n=632)$ & $1-81$ & $39.82 \pm 15.83$ & $36.58-41.06$ & $0-42$ & $12.51 \pm 5.73$ & $12.07-12.96$ \\
\hline $\operatorname{men}(\mathrm{n}=210)$ & $4-84$ & $42.05 \pm 20.20$ & $39.30-44.80$ & $0-15$ & $1.65 \pm 2.57$ & $1.30-2.00$ \\
\hline Total $(\mathrm{n}=1,182)$ & $1-90$ & $40.34 \pm 17.80$ & $39.33-41.36$ & $0-44$ & $8.71 \pm 7.27$ & $8.3-9.12$ \\
\hline
\end{tabular}

PCL: positive cutaneous leishmaniasis; NCL: negative cutaneous leishmaniasis. SD: standard deviation; 95\% CI: $95 \%$ confidence interval.

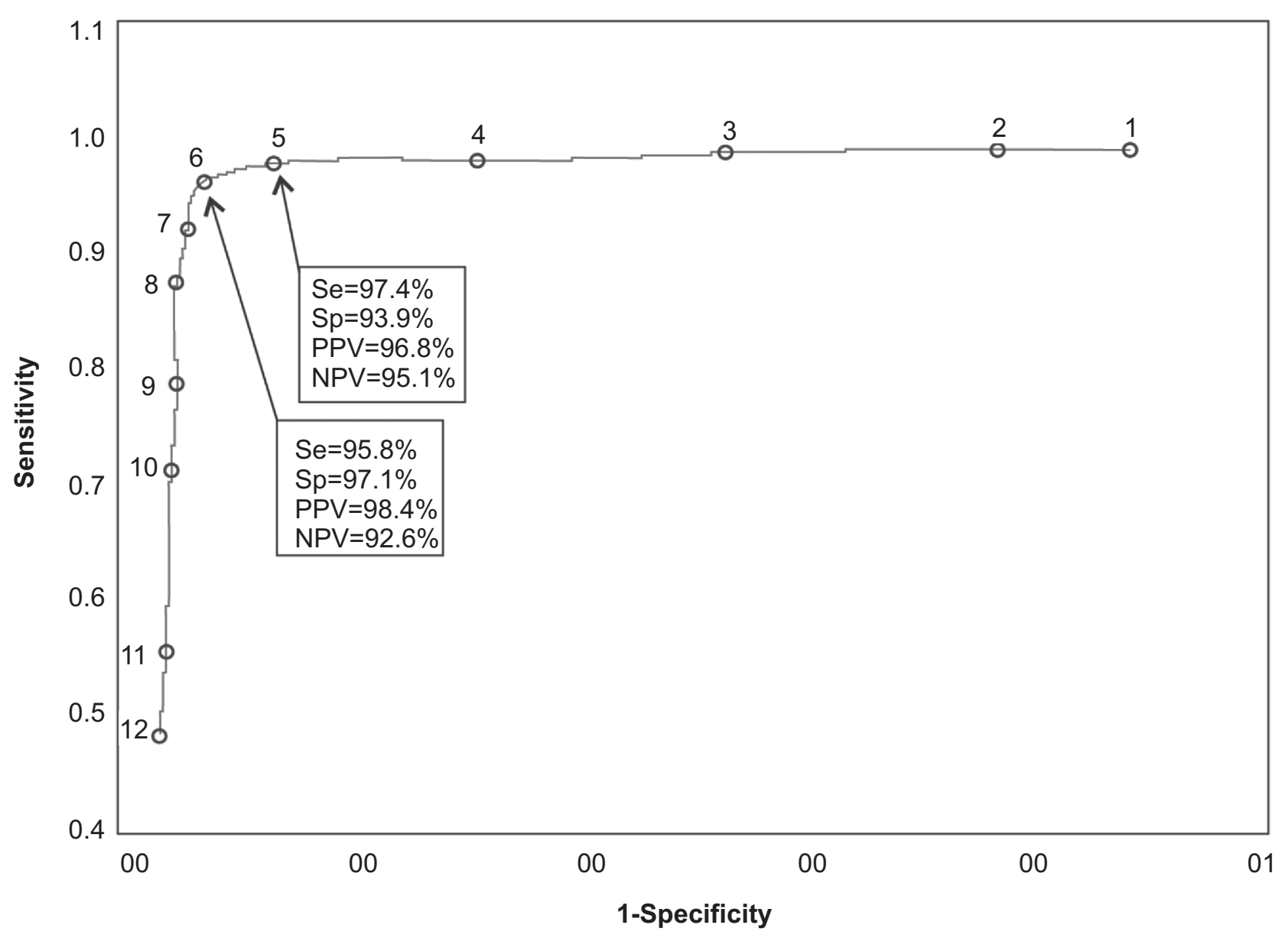

FIGURE 2 - Receiver-operating-characteristic curve for 1,182 patients in the positive cutaneous leishmaniasis and negative cutaneous leishmaniasis groups who attended LEPAC/UEM between June 1999 and February 2014. Se: sensitivity; Sp: specificity; PPV: positive predictive value; NPV: negative predictive value; LEPAC/UEM: Laboratório de Ensino e Pesquisa em Análises Clínicas, Universidade Estadual de Maringá. 


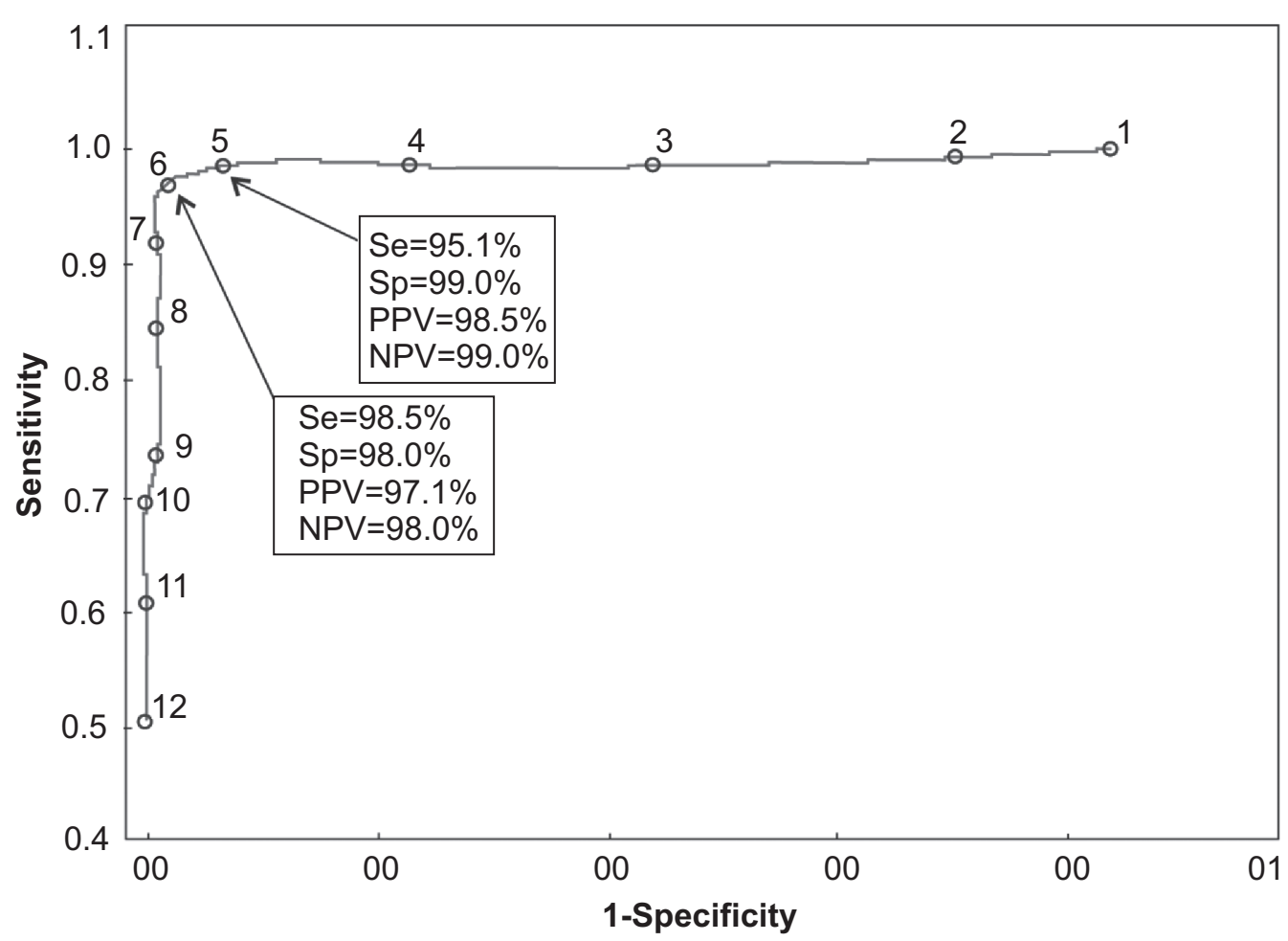

(A)

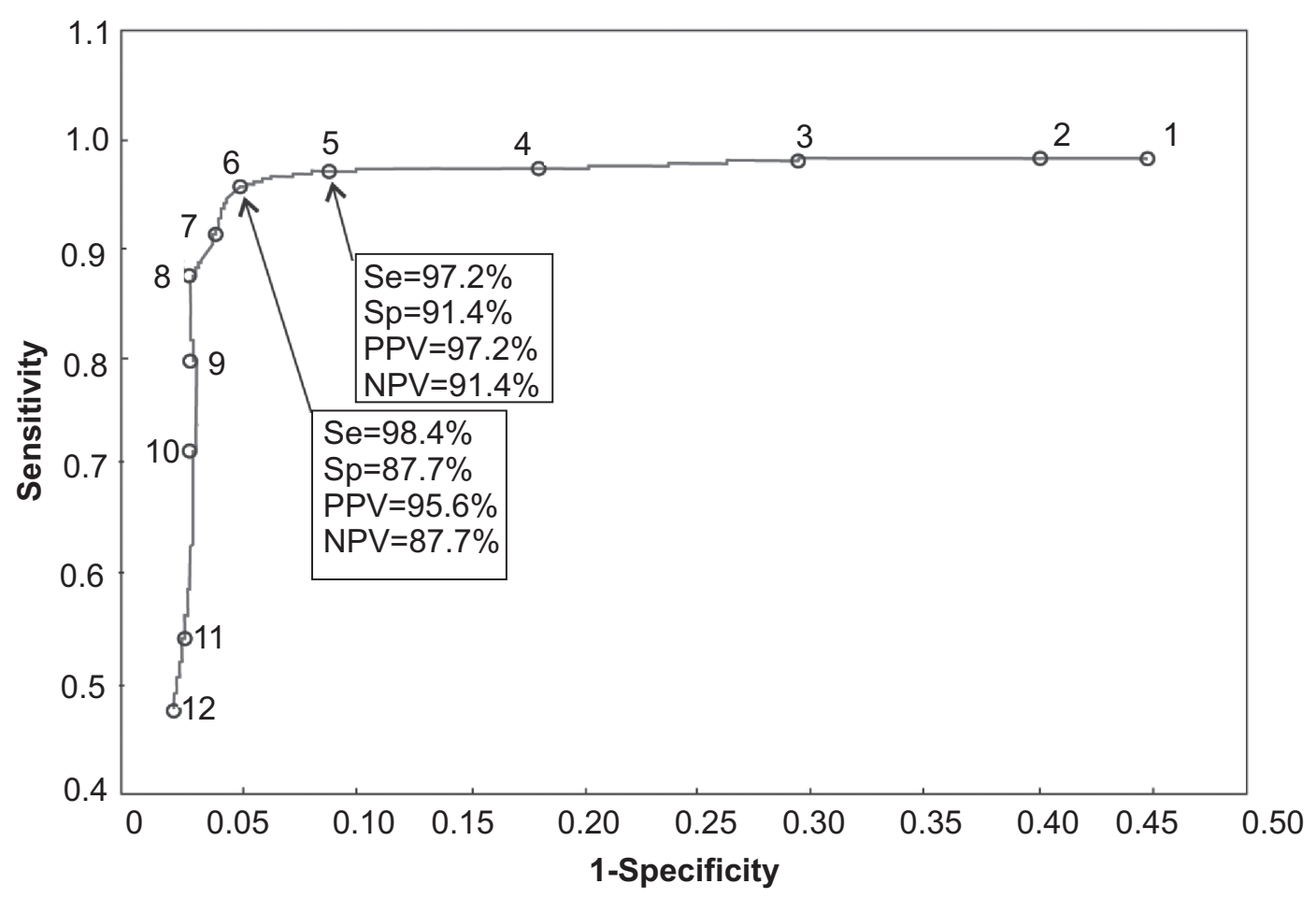

(B)

FIGURE 3 - Receiver-operating-characteristic curve for 1,182 patients in the positive cutaneous leishmaniasis and negative cutaneous leishmaniasis groups who attended LEPAC/UEM between June 1999 and February 2014 for $(\mathrm{A})$ women $(\mathrm{n}=340)$ and $(\mathrm{B})$ men $(\mathbf{n}=\mathbf{8 4 2})$. Se: sensitivity; Sp: specificity; PPV: positive predictive value; NPV: negative predictive value; LEPAC/UEM: Laboratório de Ensino e Pesquisa em Análises Clínicas, Universidade Estadual de Maringá . 

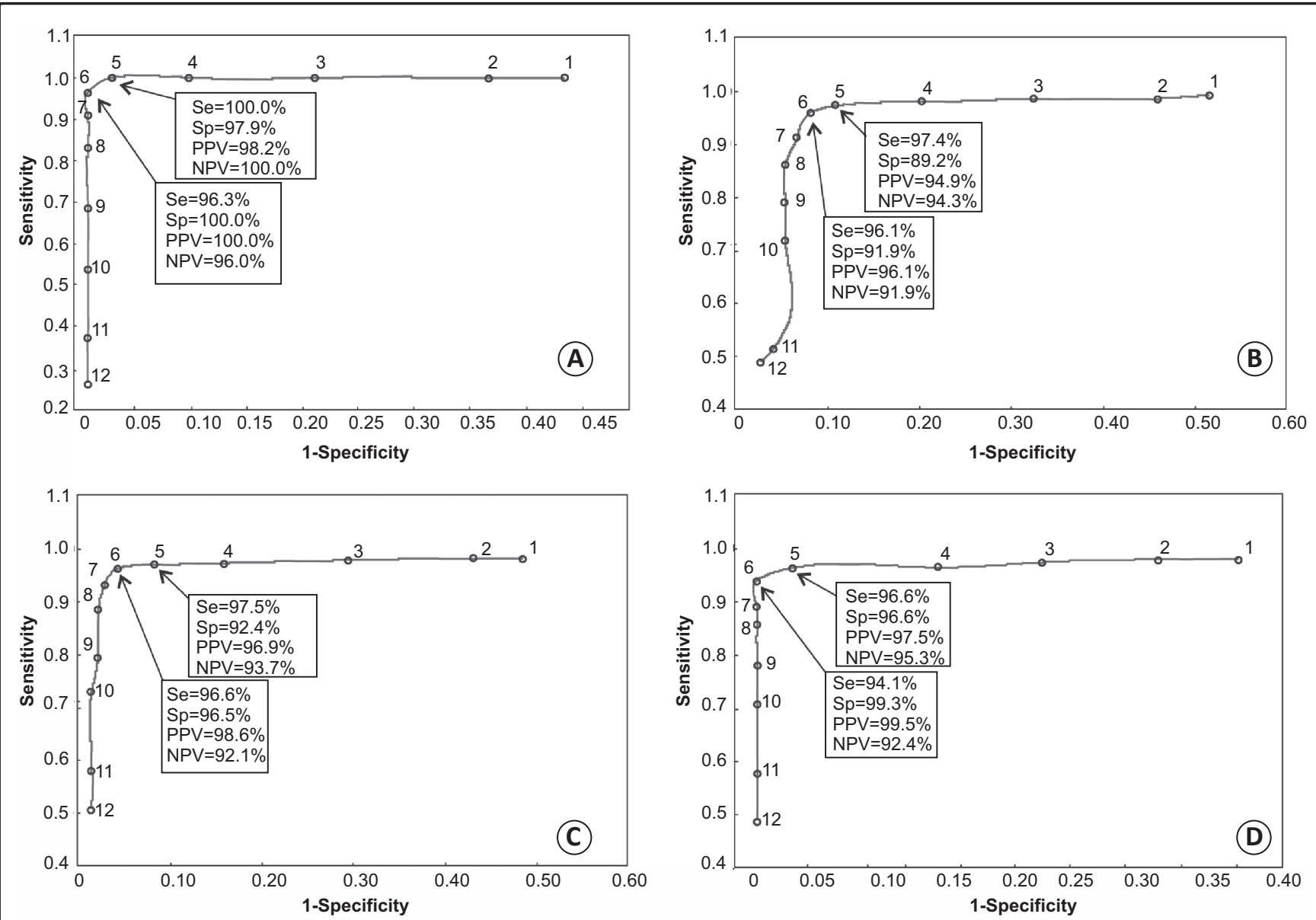

FIGURE 4 - Receiver-operating-characteristic curve for 1,182 patients in the positive cutaneous leishmaniasis and negative cutaneous leishmaniasis groups who attended LEPAC/UEM between June 1999 and February 2014 for patients aged: A. 0-14 years (n=102); B. 15-29 years $(n=228)$; C. 30-49 years $(n=502)$, and D. $\geq 50$ years $(n=350)$. Se: sensitivity; Sp: specificity; PPV: positive predictive value; NPV: negative predictive value; LEPAC/UEM: Laboratório de Ensino e Pesquisa em Análises Clínicas, Universidade Estadual de Maringá.

(95.8\% sensitivity and $97.1 \%$ specificity). Previous studies that were conducted by our research group using a $6 \mathrm{~mm}$ cut-off value for MST found $96 \%$ sensitivity among patients with positive DS results and $95.1 \%$ sensitivity among patients with positive MST, DS, and IIF results ${ }^{(19)}$. Comparatively, $90.5 \%$ sensitivity was reported in patients with a positive $\mathrm{DS}^{(14)}$, and $78.2 \%$ sensitivity and $77.4 \%$ specificity were reported in patients who attended a hospital in Peru ${ }^{(26)}$. Positive MST results were found in $93.3 \%$ of patients who had positive direct microscopic examination $^{(27)}$ and $84.4 \%$ of confirmed ATL cases from State of Paraná ${ }^{(28)}$.

In the NCL group, six $(1.5 \%)$ patients had induration diameters $\geq 10 \mathrm{~mm}$ with the MST. In endemic areas, a positive MST can be interpreted as prior leishmaniasis, prior injection of the antigen used in the test, exposure to the parasite without disease (infection), allergy to the test dilution agent, or cross-reactions with other diseases (e.g., Chagas disease, sporotrichosis, Virchowian leprosy, tuberculosis, chromomycosis, or others) ${ }^{(6)}$. Patients with sporotrichosis (12\%) had an induration diameter $\geq 10 \mathrm{~mm}$ with the $\mathrm{MST}^{(29)}$. In a nonendemic region, almost $30 \%$ of the individuals had positive reactions with the $\mathrm{MST}^{(30)}$.

For lesions lasting up to 1 month, the sensitivity was $97.5 \%$ ( $5 \mathrm{~mm}$ cut-off) or $94.9 \%$ ( $6 \mathrm{~mm}$ cut-off). For durations of 1 and 2 months, the sensitivity was $98.6 \%$ (5mm cut-off) or $97.1 \%$ ( $6 \mathrm{~mm}$ cut-off). Previous studies have reported $78 \%$ sensitivity for cutaneous lesions with a duration of up to 2 weeks and $94 \%$ and $98 \%$ sensitivities for durations of 4 and 6 weeks, respectively, in patients with positive parasitological tests; however, the MST was repeated every 7 days until a positive reaction was obtained $(5 \mathrm{~mm}$ cut-off $)^{(15)}$. Nine (1.2\%) patients and $11(1.4 \%)$ patients with lesion durations $>2$ months presented negative MST results, depending on the cut-off ( $5 \mathrm{~mm}$ and $6 \mathrm{~mm}$, respectively). A negative response with the MST after 2 months of disease evolution might be related with a defect of the host immune response ${ }^{(23)}$.

The ROC curves that were constructed according to sex showed higher sensitivity for men, which supports the findings of a previous study ${ }^{(26)}$, while higher specificity was found for 
women for both cut-off points. Regarding the positive and negative predictive values, our results agree with this previous study, with higher predictive values in women. The superior specificity and positive predictive value in women is reported to be the result of fewer false-positive results ${ }^{(26)}$. This is supported by the findings in the NCL group in the present study, in which $18(8.6 \%)$ men and 7 (3.3\%) women had induration diameters $\geq 5 \mathrm{~mm}$ with the MST.

The ROC curves for the different age groups showed that the $0-14$ years old had a better curve, and both cut-off values ( 5 and $6 \mathrm{~mm}$ ) could be used. The individuals in this age group were likely not to have encountered many antigens yet, which would provide a more specific response with the MST. In a previous study, a $63.2 \%$ sensitivity for patients $<12$ years of age, $100 \%$ for patients $12-18$ years of age, and $60 \%$ for patients $\geq 65$ years of age have been reported ${ }^{(26)}$. Although the age stratification was different, our results using a cut-off of $5 \mathrm{~mm}$ showed higher sensitivities for the specific age groups $(100 \%$ for patients $0-14$ years old, $97.4 \%$ for patients $15-18$ years old, $97.5 \%$ for patients $30-49$ years old, and $96.6 \%$ for patients $\geq 50$ years old).

The present study evaluated the response to the MST in a population from an ATL endemic area in the northern and northwestern regions of the State of Paraná, Brazil. The results showed $97.4 \%$ sensitivity and $93.9 \%$ specificity for the $5 \mathrm{~mm}$ cut-off and $95.8 \%$ sensitivity and $97.1 \%$ specificity for the $6 \mathrm{~mm}$ cut-off, with higher sensitivity in men, higher specificity and predictive values in women, and the best curves for both the 5 and $6 \mathrm{~mm}$ cut-off values in $0-14$ years old. Considering the need to balance sensitivity and specificity, both cut-off values ( 5 and $6 \mathrm{~mm}$ ) could be used in this population. It would also be interesting to investigate the cut-off values for the MST in populations from other ATL endemic areas.

\section{ACKNOWLEDGMENTS}

We offer our deepest thanks to the institutions that provided technical support for the development and implementation of this study, especially to the pharmaceutical-biochemical Eneide Aparecida Sabaini Venazzi and Paulo Donizeti Zanzarini.

\section{CONFLICT OF INTEREST}

The authors declare that there is no conflict of interest.

\section{FINANCIAL SUPPORT}

This work received financial support from Fundação Araucária, Conselho Nacional de Desenvolvimento Científico e Tecnológico (CNPq), Coordenação de Aperfeiçoamento de Pessoal de Nivel Superior (CAPES) and Laboratório de Ensino e Pesquisa em Análises Clínicas of the Universidade Estadual de Maringá (LEPAC/UEM).

\section{REFERENCES}

1. World Health Organization (WHO). Leishmaniasis. Geneva, Swirtzerland: WHO; 2012. (Accessed 2014 May 6). Available at: http://www.who.int/leishmaniasis/en

2. Ministério da Saúde. Casos de Leishmaniose Tegumentar Americana. Brasil, Grandes Regiões e Unidades Federadas. 1990 a 2013. Brasília: Ministério da Saúde; 2014. (Accessed 2014 September 15). Available at: http://portalsaude.saude.gov.br/ images/pdf/2014/setembro/09/LT-Casos.pdf

3. Lima AP, Minelli L, Communello E, Teodoro U. Distribuição da leishmaniose tegumentar por imagens de sensoriamento remoto orbital, no Estado do Paraná, Sul do Brasil. An Bras Dermatol 2002; 77:681-692.

4. Marzochi ACA, Marzochi KBF. Tegumentary and visceral leishmaniasis in Brazil - emerging anthropozoonosis and possibilities for their control. Cad Saude Publica 1994; 10 (supl II):359- 375.

5. Andrade BB, Boaventura V, Barral-Neto M, Barral A. Métodos Diagnósticos da leishmaniose tegumentar: fatos, falácias e perspectivas. Gaz Med Bahia 2005; 75:75-82.

6. Ministério da Saúde, Secretaria de Vigilância em Saúde, Departamento de Vigilância Epidemiológica. Manual de vigilância da leishmaniose tegumentar americana. $2^{\text {nd }}$ ed. Brasília: Ministério da Saúde; 2013. p. 180.

7. Gontijo B, Carvalho MLR. Leishmaniose tegumentar americana. Rev Soc Bras Med Trop 2003; 36:71-80.

8. Montenegro J. Cutaneous reaction in leishmaniasis. Arch Dermatol Syphilol 1926; 13:187-194.

9. Carvalho EM, Correia Filho D, Bacellar O, Almeida RP, Lessa $\mathrm{H}$, Rocha $\mathrm{H}$. Characterization of the immune response in subjects with self-healing cutaneous leishmaniasis. Am J Trop Med Hyg 1995; 53:273-277.

10. Sokal JE. Measurement of delayed skin-test responses. New Eng J Med 1975; 293:501-502.

11. Hailu A, Berthe N, Ali A, Gemetchu T. Use of Leishmania major derived leishmanin skin test surveys of visceral leishmaniasis in Ethiopia. East Afr Med J 1997; 74:41-45.

12. Arana BA, Roca M, Rizzo NR, Mendoza CE, Kroeger A. Evaluation of a standardized leishmanin skin test in Guatemala Trans R Soc Trop Med Hyg 1999; 93:394-396.

13. Basano AS, Camargo LMA. Leishmaniose tegumentar Americana: histórico, epidemiologia e perspectivas de controle. Rev Bras Epidemiol 2004; 7:328-337.

14. Sadeghian G, Momeni A, Siadat AH, Yousefi P. Evaluation of leishmanin skin test and its relationship with the clinical form and duration of cutaneous leishmaniasis. Dermatol Online J 2006; 12:3.

15. Manzur A, Bari A. Sensitivity of leishmanin skin test in patients of acute cutaneous leishmaniasis. Dermatol Online J 2006; 12:2.

16. World Health Organization (WHO). The control of the leishmaniases. WHO Technical Report Series n 949. Geneva, Swirtzerland: WHO; 2010. (Accessed 2014 October 8). Available at: http://www.who.int/ leishmaniasis/research/978924129496_pp67_71.pdf?ua=1

17. Alimohammadian MH, Jones SL, Darabi H, Riazirad F, Ajdary S, Shabani A, et al. Assessment of Interferon- $\gamma$ Levels and Leishmanin Skin Test Results in Persons Recovered for Leishmaniasis. Am J Trop Med Hyg 2012; 87:70-75. 
18. Arraes SMAA, Silveira TGV, Lonardoni MVC, Ramos M, Bertolini DA, Dias MLG. Avaliação da intradermorreação de Montenegro: comparação entre dois antígenos de diferentes procedências. Rev Unimar 1991; 13:5-19.

19. Silveira TGV, Arraes SMAA, Bertolini DA, Teodoro U, Lonardoni MVC, Roberto ACBS, et al. Observações sobre o diagnóstico laboratorial e a epidemiologia da leishmaniose tegumentar no Estado do Paraná, sul do Brasil. Rev Soc Bras Med Trop 1999; 32:413-423.

20. Curti MCM, Silveira TGV, Arraes SMAA, Bertolini DA, Zanzarini PD, Venazzi EAS, et al. Epidemiological and clinical characteristics of cutaneous leishmaniasis and their relationship with the laboratory data, south of Brazil. Braz J Infec Dis 2011; 15:12-16.

21. Centro de Produção e Pesquisa de Imunobiológicos (CPPI). Antígeno de Montenegro. Bula do antígeno; Paraná; 2008. (Accessed 2014 September 14). Available at: http://www.saude. pr.gov.br/arquivos/File/CPPI/bulas/montenegro.pdf

22. Weigle KA, Valderrama L, Arias AL, Santrich C, Saravia NG. Leishmanin skin test standardization and evaluation of safety, dose, storage, longevity of reaction and sensitization. Am J Trop Med Hyg 1991; 449:260-271.

23. Antonio LF, Fagundes A, Oliveira RVC, Pinto PG, BedoyaPacheco SJ, Vasconcellos ECF, et al. Montenegro skin test and age of skin lesion as predictors of treatment failure in cutaneous leishmaniasis. Rev Inst Med Trop São Paulo 2014; 56:375-380.
24. José FF, Silva IM, Araújo MI, Almeida RP, Bacellar O, Carvalho EM. Avaliação do poder sensibilizante da reação de Montenegro. Rev Soc Bras Med Trop 2001; 34:537-542.

25. Murback NDN, Nascimento RAF, Dorval MEMC, Hans Filho G, Nakazato KRO. Leishmaniose tegumentar Americana: estudo clínico, epidemiológico e laboratorial realizado no Hospital Universitário de Campo Grande, Mato Grosso do Sul, Brasil. An Bras Dermatol 2011; 86:55-63.

26. Boggild AK, Ramos AP, Espinosa D, Valencia BM, Veland N, Miranda-Verastegui C, et al. Clinical and Demographic Stratification of Test Performance: A Pooled Analysis of Five Laboratory Diagnostic Methods for American Cutaneous Leishmaniasis. Am J Trop Med Hyg 2010; 83:345-350.

27. Hashemi SN, Mohebali M, Mansouri P, Bairami A, Hajjaran H, Akhoundi B, et al. Comparison of Leishmanin Skin Test and Direct Smear for the Diagnosis of Cutaneous Leishmaniasis. Acta Med Iran 2011; 49:136-141.

28. Pontello Jr R, Gon AS, Ogama A. American cutaneous leishmaniasis: epidemiological profile of patients treated in Londrina from 1998 to 2009. An Bras Dermatol 2013; 88:748-753.

29. Barros MBL, Schubach A, Francesconi-Dovalle AC, GutierrezGalhardo MC, Schubach TMP, Conceição-Silva F, et al. Positive Montenegro skin test among patients with sporotrichosis in Rio de Janeiro. Acta Trop 2005; 93:41-47.

30. Fagundes A, Marzochi MCA, Perez M, Schubach A, Ferreira A, Silva JP, et al. Skin reactivity to thimerosal and phenol-preserved Montenegro antigen in Brazil. Acta Trop 2007; 101:25-30. 